\title{
Research on the Application of Automatic Scoring System in College English Writing
}

\author{
Weiwei Qu \\ Teaching and Research Institute of Foreign Languages, Bohai University, Jinzhou, 121013, China \\ syquwei@yeah.net
}

Keywords: automatic scoring system; college English; English writing; application research; scoring model; application suggestions

\begin{abstract}
Automatic evaluation system of composition is based on artificial intelligence and natural language technology, through the computer and network to evaluate written composition, and put forward the improvement suggestion of application software, is mainly used in large scale composition test score. In order to promote the application of automatic scoring system in college English writing, this paper mainly studies the related issues. The research content mainly includes five aspects: shows the typical automatic scoring system, design the system function, build the evaluation model, put forward the proposals, analyses the application effect. With the constant improvement of the education informatization level, automatic scoring system in college English writing teaching must get more and more widely used.
\end{abstract}

\section{Introduction}

College English writing and reading comprehension, oral English and listening comprehension are in the equally important position. But because of "Dumb English" is outstanding, in English teaching experts and teachers focus on improve the oral English teaching and oral expression ability, writing teaching and writing ability is not valued. In fact, the content of the English writing ability is very important, through writing can continuously consolidate knowledge and improve their English skills. The actual college English writing teaching, the teacher corrects the composition of burden, correcting cycle is long, student writing less volume, directly affects the improvement of students' writing level. Automatic composition evaluation system is achieved by computer and network to evaluate written composition, and put forward the improvement suggestion of application software, is mainly used in large scale composition test scores, has the advantages such as fast and save Labor, to avoid interference with human factors, the review results more objective $[1,2]$. In order to promote the application of automatic scoring system in college English writing, this paper studies the related issues.

\section{Typical Automatic Scoring System}

This is respectively explanation on foreign and domestic typical automatic scoring system [3-7]:

Abroad: (1) PEG (Project Essay Grader) is the oldest automatic grading composition software, mainly analyze the writing form, only measure the quality of the language of the composition, application of regression principle of statistics, on the surface of the works of some easy to quantify variables (length, word length, punctuation, and grammar, etc.) as the independent variables, to work the scores as the dependent variable, due to the works by observing some quantifiable factors. (2) IntelliMetric of natural language understanding is to support the essay scoring system, the first to use artificial intelligence, as well as using natural language and statistical techniques, scoring system based on artificial intelligence applications. Text from the perspective of grammatical analysis, the analysis of parts of speech and syntactic relations between each other, a process that helps IntelliMetric give according to the main characteristics of standard written English composition score. (3) IEA (Intelligent Essay Assessor) is a kind of automatic scoring system based on latent semantic analysis of composition, main composition analysis of the text content and students in the convey of knowledge, rather than writing style or language. The latent semantic 
analysis is used in the automatic grading students composition, the happy to score composition with pre-arranged pick-up is viewed as a vector, the vector comparison, be able to get every happy to score the composition and the degree of similarity in content score.

Domestic: (1) The Cool Correcting Network, provides English composition correcting service, service for university teachers and students, in recent years has expanded to the high school students, through training grade engine, automatically according to the level 4 or level 6, the college entrance examination, and the composition of the examination criteria, to automatically correcting students' composition, grading, and expressed in grammar, diction, non-standard place to give feedback, modify advice to students. (2) The New Horizon College English composition automatic scoring system, is a new field of vision composition assessment tools, online learning platform using the university English four levels and six levels of writing criteria, set a score of 1 to 15 points, can carry on the automatic grading English composition on any subject, calculate the total number of words and give comments. (3) Automatic scoring system, large-scale exam English composition by extracting shallow text characteristic, the content of latent semantic analysis, and using the linear regression, scores are obtained. Although the results achieved with human raters high relevance, but because is given priority to with a statistical analysis of the characteristics of shallow, and sample size, scope, limitations, there are a certain distance with practical systems.

\section{Functional Design}

Software function is a software should have the efficiency and effect, software goal through software functions to express and implementation, software function and software is presented to the user directly effect. User through software provides functions to understand, use and evaluation system, through the use of the software functions to complete the operation. Functional requirement is the most important content of requirements analysis. Functional analysis is based on software, form with the results of the model of the software functions, and quantitative or qualitative description of the functions of the software is put forward. Functional design result is expressed in structure. Chart of a rectangular box represents a module, a rectangular box attachment represent the relationship between, is located in the upper rectangle represents module, call in the rectangular box below on behalf of the module. Automatic scoring system has the double function of writing and grading, system function design result is shown in Fig. 1.

As shown in Fig. 1 consists of seven main modules, function structure and under each main module contains several sub modules. Briefly describe the main modules are as follows: the Resource center, auxiliary English writing for students of all kinds of resources; Collaborative learning, for students to engage in learning activities in the form of cooperation and mutual way; Student writing to students English writing and submitting online works; Automatic evaluation, the system automatically works for students to evaluate the information such as the grammar, syntax and discourse; Works of the Teacher evaluation, the Teacher to the student's language ability and pragmatic ability and writing level evaluation; Student query, the Student works online query and evaluation and other related information; Data management, teachers and administrators maintain on the system information [8].

\section{Scoring Model Construction}

Model is by subjective consciousness in the physical or virtual, constitute the objective in this paper, the morphology and structure of an express purpose of affair, can be a solid model, but also can be a virtual model. Model can help people to recognize and understand some things that cannot be directly observed or complex. Model method is the most powerful, most convenient and most effective method for people to understand and explore the objective world. In scientific research, people with certain scientific method, to establish a suitable model to reflect and take the place of the objective object, and through the research on this model to prompt the objective form, features and nature of objects. Using artificial intelligence technology, especially natural language 
processing and intelligent language coaching technology, build a new writing automatic grading model shown in Fig. 2 [9].

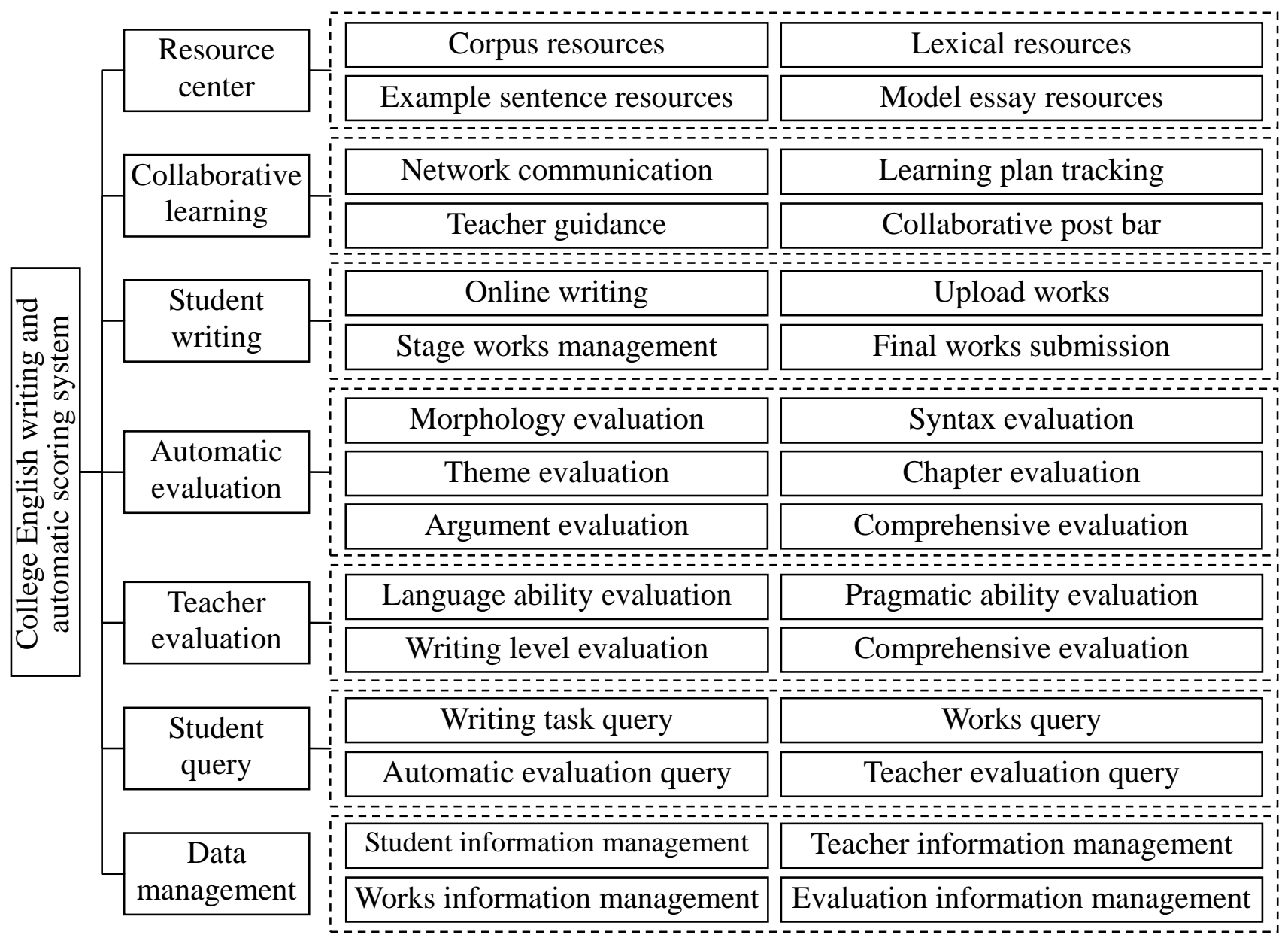

Fig. 1. Function on college English writing and automatic scoring system

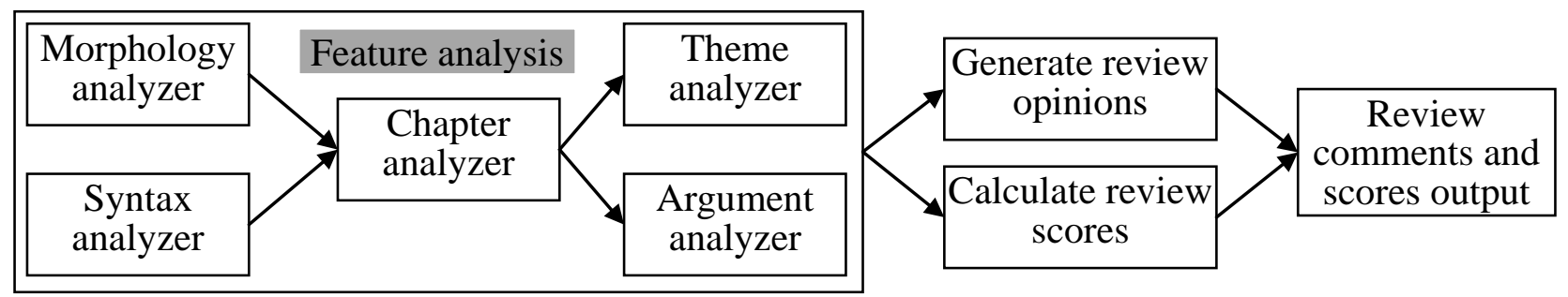

Fig. 2. Model on English writing automatic scoring

In Fig. 2, the characteristic analysis is a basic work for the automatic scoring system, made up of five analyzers. Among them, the one is, the lexical analyzer, a work of word form and its usage are analyzed. English parts of speech in the form of nouns and pronouns number, and the change of sex in the form of change; Verb person, tense, voice, tone, and other forms of change; As well as changes in the form of adjectives and adverbs comparative level. Second, syntax analyzer, analyzing the sentences in each part and the law of the arrangement; Three is chapter analyzer, the study of natural language text of the internal structure and understand the semantic relationship between the text unit, is a kind of text analysis of words and sentences after granularity, need an analysis of the global context [10]. Four is that theme analyzer, analyze the process of thematic elements and theme center. A theme is often expressed by some combination of the concept of unit, the theme of the concept of unit form is thematic elements and important part is the center theme. Five is that argument analyzer, argument is that the author views and propositions on discussed problem, is the author of works on the proposed opinions, and attitude. Analyze the argument is 
helpful to broaden the train of thought. According to the characteristics of the analysis of the results generated review opinions and calculate the review scores, then output review opinions and score.

\section{Application Suggestions}

Application strategy focuses on two aspects of teachers and students put forward:

(1) Teachers: the role of the teacher in the writing teaching are indispensable, teachers' consciousness, ability and level directly affect the students' English writing level. To teacher put forward the application of advice is as follows: attach importance to the role of feedback in English writing teaching, the feedback as an important part in the process of teaching, penetrated into every link in the process of writing, try to be every time writing can timely feedback, we not only provide feedback from the aspects of language knowledge, more from the perspective of writing ideas; Choose the writing subject, try to decorate their lives and make students interested in the topic; Pay attention to student writing, sentences and discourse the students lack language knowledge, pay attention to in training students' language knowledge on the basis of focus on cultivation of discourse awareness. To cultivate students for a variety of genre of English discourse mode of thinking, to help students establish the concept of discourse, develop students' logical thinking, writing training starting to imitate good English article; From the concept of humanism, for students to create a relaxed, free and harmonious English learning environment, encourage students to actively participate in writing activities, stimulate the learning potential, improve writing level [11].

(2) Students: students are the main body of writing, only by constantly strengthen its own writing consciousness, and constantly improve the level of English writing. Applications are as follows: to students' value system to provide feedback, to strengthen the processing and application of feedback information. The effectiveness of feedback depends on whether the learners have really thought about these feedbacks, if you really think, to notice the language problem, seriously every time writing. Writing the topic assigned by teachers has a specific training purpose, not necessarily completely accords with the interests of individual students. For the topic of interest to fully conceived, play English knowledge. For less interested in the topic, but also through various channels to collect material carefully to complete all aspects; Insist on the way and rewrite, form a good habit of writing, improve writing ability in the process of modifying and rewrite, cultivate independence, autonomy and innovation; Correct mindset, the right attitude towards positive feedback and negative feedback, according to the feedback on the earnest revision, get exercise and improve in the modification process. Improve conversion mode of thinking, discourse writing awareness and the ability of discourse writing.

\section{Application Effects}

Automatic scoring system in college English writing the application effect is briefly summarized as follows:

(1) Writing teaching focus from language error correcting to focus on the content of the work itself, structure and expression. Because the system can point out and help students to change the language errors, teachers have learned before correcting the system preliminary evaluation of the work, don't have to spend time revising low-level mistakes in grammar and can put more energy on writing teaching itself.

(2) Realized based on the understanding and using of assessment standard. Automatic scoring system based on native speakers of English corpus as the basic standard of students, from writing content, structure, diction, sentence structure, style, grammar and writing format and specification and so on to analyze works, grading, feedback report and writing auxiliary functions in one.

(3) The students' autonomous learning ability was improved. under the guidance of teachers, students understand and use of writing evaluation standards, and in the system of writing and constant revision based on feedback, to cultivate the writing ability and the capacity for independent modification works, in the modification process was improved.

(4) Promote the development of the students' writing interest and autonomy. With the change of 
the teaching mode, the students gradually become the study master, teachers are no longer is the transmission of knowledge, but rather guide and helper, and students to change on their own work, actively to seek help, greatly play learning potential, further improve the ability of autonomic learning.

\section{Conclusion}

Automatic scoring system compared with the traditional manual assessment method has obvious advantages: repeat operation and not feel tired, have a good adaptability and flexibility; Review process is not affected by personal factors and working environment, has the high reliability, scoring process more fair and efficient; Is a teacher to save time, reduce the labor intensity and improve work efficiency good helper; Marking process has the advantages of real-time, fast speed and fuel economy. With the constant improvement of the education informatization level, automatic scoring system in college English writing teaching must get more and more widely used.

\section{Acknowledgement}

This work is supported by 2015 annual "Twelfth Five Year" Education and Science Planning Project in Liaoning Province (JG15DB026): Application Research on Automatic Scoring System in College English Writing.

\section{References}

[1] L. Zhou, "A study of the influence of English writing platform on College Students' English writing ability," Journal of The Chinese Society of Education, vol. 36, no. 1, pp. 283-285, 2015.

[2] Y. Chen, "Empirical Study of Application of Automated Essay Scoring System in College English Writing Teaching," Journal of Jixi University, vol. 12, no. 10, pp. 102-104, 2012.

[3] J. L. Tang, Y. A. Wu, "Using automated writing evaluation in classroom assessment: A critical review," Foreign Language Teaching and Research, vol. 43, no. 2, pp. 273-282, 2011.

[4] M. C. Liang, Q. F. Wen, "Comments on the automatic scoring system of composition in foreign countries and Its Enlightenment," Computer-Assisted Foreign Language Education, vol. 29, no. 5, pp. 18-25, 2007.

[5] X. X. Chun, "Review of the System of Automated Essay Scoring and Discussion of Its Reliability, Validity and Operability," Journal of Jiangxi Normal University (Philosophy and Social Sciences Edition), vol. 43, no. 2, pp. 136-140, 2010.

[6] Y. Y. Wang, "A study on the validity of the automatic scoring system of College English in the new horizon," Theory and Practice of Contemporary Education, vol. 4, no. 12, pp. 139-142, 2012.

[7] X. P. Wu, "Review and development of network composition automatic scoring system," Educational information, vol. 57, no. 34, pp. 38-39, 2014.

[8] H. L. Qiao, "A Study on College English Writing Teaching Based on AES," Master's degree of Northeast Petroleum University, 2014.

[9] X. L. Shi, "A Tentative Study on the Validity of Online Automated Essay Scoring Used in the Teaching of EFL Writing," Modern Educational Technology, vol. 22, no. 10, pp. 67-71, 2012.

[10] F. Xu, Q. M. Zhu, G. D. Zhou, "Survey of Discourse Analysis Methods," Journal of Chinese Information Processing, vol. 27, no. 3, pp. 20-32, 2013.

[11] J. L. Tang, "How to integrate an automated writing assessment tool in the EFL classroom," Foreign Language Learning Theory and Practice, vol. 34, no. 1, pp. 49-57, 2014. 